\title{
Relationship between risk perception and occupational accidents: a study among foundry workers
}

\author{
Mohammad Javad Jafari ${ }^{1}$ (D) Fahimeh Saghi ${ }^{i^{*}}$ (D), Ebrahim Alizadeh ${ }^{2}$ (D) and Farid Zayeri ${ }^{3}$ (D)
}

\begin{abstract}
Background: Risk perception is an effective factor in the determining of the incidence of unsafe behaviors and the occurrence of occupational accidents in the workplace.

Objective: The purpose of this study is to determine the relationship between risk perception and occupational accidents among foundry workers in Tehran, Iran.

Methods: In this cross-sectional study, all male workers in a foundry unit were initially selected $(n=245)$. After applying the study criteria and dismissing incomplete returned questionnaires, only 109 workers were included in the study. The General Health Questionnaire and the Flynn et al. Risk Perception Questionnaire were used to assess the mental health and risk perception of workers, respectively. Data regarding the occupational accidents of workers were also extracted from the accidents' records of the foundry. Workers with a record of occupational accidents during 2013-2016 were compared with workers without an occupational accident record.

Results: Findings showed that a one-unit increase in the risk perception score resulted into an increase of approximately $33 \%$ in the odds of the occurrence of occupational accidents, but this rate was not significant $(p=0.695)$. In addition, the study found no significant relation between the risk perception score and the frequency of occupational accidents (Spearman's $r=0.003, p=0.977$ ).

Conclusion: There is no statistically significant relationship between risk perception and occupational accidents among foundry workers in Tehran, Iran.
\end{abstract}

Keywords: Accidents, Occupational, Perception, Risk

\section{Introduction}

Occupational accidents are of major concern in both developed and developing countries because of their detrimental effects on health, society, and economy [1]. According to an estimation carried out by the International Labor Organization, approximately 340 million occupational accidents occur annually throughout the world [2]. Therefore, it is essential that preventive

\footnotetext{
* Correspondence: fahimehsaghi@yahoo.com

${ }^{1}$ Department of Occupational Health Engineering, School of Public Health and Safety, Shahid Beheshti University of Medical Sciences, Tehran, Iran Full list of author information is available at the end of the article
}

programs consider the causes of occupational accidents and the underlying factors affecting them.

Risk perception is defined as "an individual's subjective judgment about the characteristics and severity of risks" [3]. Risk perception is one of the human features that affect an individual's behavior in as such that the incorrect perception of risks is considered as a factor in the incidence of unsafe behaviors [4-6]. An increase in the level of an individual's risk perception leads to an increase in the incidence of safe behaviors [4].

Studies have shown that unsafe behaviors are the major cause of occupational accidents [1, 7] and poor or incorrect perception of a workplace's risks (or even the lack of risk perception) is a factor contributing to the incidence of occupational accidents $[1,3,8]$. 
During the casting process in a foundry, workers are exposed to various hazards (such as noise, pollution, vibration, or heat) or accidents (such as explosions, fires, or burns) [9]. The present study aimed at determining the relationship between risk perception and the occurrence and frequency of occupational accidents among workers of a foundry unit in Tehran, Iran, in 2016.

\section{Methods}

\subsection{Study design and participants}

In this cross-sectional analytical study, all male workers $(n=245)$ in a foundry unit in Tehran were initially included as the study population. The inclusion criteria were as follows: having a mental health score of $0-22$ in the 28-item General Health Questionnaire, and having at least 3 years of job experience in the unit (as workers' occupational accidents over 3 years will be investigated). The attrition effect of the workers was considered as study exclusion criteria. After applying the study criteria and dismissing incomplete returned questionnaires, only 109 workers were included in the study. Data was collected during June to September 2016.

\subsection{Tools}

\subsubsection{Questionnaires}

The workers completed the questionnaires in the form of self-reporting. The 28-item General Health Questionnaire has been used to determine the severity of the individual's mental disorders [10]. This questionnaire consists of four subscales: "somatic symptoms," "anxiety," "social dysfunction," and "depression" [11]. The validity of the Persian version of this questionnaire (Nazifi et al.) showed that Cronbach's alpha coefficient for the somatic symptoms, anxiety and insomnia, social dysfunction, severe depression, and questionnaire's total scale were $0.865,0.883$, $0.746,0.897$, and 0.923 , respectively [12]. In the study by Yaghoubi et al., [11] and Noorbala and Mohammad [13], the reliability coefficient of this questionnaire has also been reported as 0.88 and 0.91 respectively. The total score ranges from 0 to 84 . A score of $0-22$ in the 28 -item General Health Questionnaire indicates that there is no (or minimum) level of mental disorder in the worker. A score range of 23-40 is considered mild, $41-60$ is moderate, and 61-84 is considered as severe mental disorders [10].

The Flynn et al. Risk Perception Questionnaire has been used to assess an individual's risk perception. This questionnaire consists of two major parts: (a) general information and (b) 133 questions divided into 10 separate sections (entitled in order as "job situation," "the physical conditions of working environment," " the experience of risk-hazards," "the probability of injury," "the experience of risk-work tasks," "job satisfaction," "the assessment of safety," "safety and accidents prevention," "personal support and receiving help from others," and "the experience of accidents and near-misses." This questionnaire was validated by Soltani in Iran (2016). The content validity ratio, the content validity index, and Cronbach's Alpha coefficient of this questionnaire were reported as $0.77,0.96$, and 0.93 , respectively. The average of all scores for the domains of the Risk Perception Questionnaire was considered as the risk perception score. After evaluation, the worker receives a score of 1-5 (the minimum and maximum scores of the perception risk are 1 and 5, respectively) [14].

\subsubsection{Records}

The data related to the occupational accidents of workers (the occurrence of occupational accidents and the frequency of accidents) were extracted from the records of occupational accidents of the foundry. In order to obtain adequate information and generalizable inference, the data related to the occupational accidents over a consecutive 3-year period (2013-2016) was extracted. The workers with an occupational accidents' record during 2013-2016 were compared with the workers without an occupational accident record (in terms of job category, age, and job experience).

\subsubsection{Occupational accidents}

In this study, occupational accident occurrence was defined as any occupational accident which has occurred (i.e., the occurrence or non-occurrence of accidents). The occupational accidents frequency for each worker was determined by counting the number of occupational accidents that had occurred over the past 3 years (from 2013 to 2016) for the individual.

\subsection{Statistical analysis}

In this research, the studied variables were risk perception score, occupational accident occurrence, and occupational accident frequency. The collected data were analyzed using the IBM SPSS software, version 19.0. In order to describe the quantitative variables, the mean and standard deviation were used. The frequency distribution was also utilized to describe the categorical variables. The Kolmogorov-Smirnov test was used to assess the normality of the distribution of the variables. In order to compare the risk perception score between two groups of workers (injured and non-injured workers), the independent sample $t$ test was used. Logistic regression was also applied to determine the relationship between risk perception score and the occurrence of occupational accidents. Regarding the normal distribution of risk perception score and the non-normal distribution of occupational accident frequency, the Spearman correlation coefficient was used to determine the association between risk perception score and occupational accident frequency. In all statistical analyses, $p$ values less than 0.05 were considered as statistically significant. 


\section{Results}

\subsection{Participant characteristics}

In this study, all workers $(N=109)$ were males. Most of them were married (93.6\%) and the majority was educated up to the level of diploma (72.5\%). The demographic variables of workers are presented in Tables 1 and 2 .

\subsection{Occupational accidents}

Table 3 shows the frequency distribution of workers by the occurrence of occupational accidents. Less than half of the workers (46.8\%) had ever experienced occupational accidents.

Table 4 shows the frequency distribution of occupational accidents among injured workers in the foundry. The majority experienced one accident while none of the injured workers had experienced five or six occupational accidents.

\subsection{Risk perception}

The risk perception score is slightly higher among injured workers than those who had not been injured, but this difference was not statistically significant, as shown in Table 5.

\subsection{Relationship between risk perception and occupational accidents}

Table 6 shows the results of investigating the relationship between risk perception score and occupational accident occurrence. With a single unit increase in the risk perception score, the odds of occupational accident occurrence increased by about 33\%; however, this rate was not statistically significant.

In this study, the distribution of the workers' risk perception score and the distribution of the workers' occupational accident frequency was normal and non-normal, respectively. Thus, in order to determine the association between the risk perception score and occupational accident frequency, the Spearman correlation coefficient was used. This coefficient showed that there is no statistically significant relationship between the risk perception score and occupational accident frequency (Spearman's $r=0.003, p=0.977$ ).

\section{Discussion}

The present study was performed with the aim of determining the relationship between risk perception and

Table 1 Descriptive statistics for quantitative demographic variables of foundry workers ( $N=109)$ in Tehran, Iran, 2016

\begin{tabular}{llll}
\hline Variables & Min & Mean \pm SD & Max \\
\hline Age (year) & 28 & $39.15 \pm 5.22$ & 57 \\
Job experience $^{1}$ (year) & 3 & $12.84 \pm 5.49$ & 26 \\
Work experience $^{2}$ (year) & 5 & $14.59 \pm 5.07$ & 26 \\
\hline
\end{tabular}

${ }^{1}$ The duration of employment in the current job

${ }^{2}$ The duration of employment in the current job and other jobs
Table 2 Distribution of categorical demographic variables of foundry workers ( $N=109)$ in Tehran, Iran, 2016

\begin{tabular}{ll}
\hline Variables & $\mathrm{N}(\%)$ \\
\hline Job type & $28(25.7)$ \\
Machining & $4(3.7)$ \\
Sand cycle operator & $3(2.7)$ \\
Core production operator & $50(45.9)$ \\
Cast iron production operator & $3(2.7)$ \\
Shift supervisor & $9(8.3)$ \\
Melt operator & $12(11.0)$ \\
Technical and Maintenance & \\
Education & $23(21.1)$ \\
Below diploma & $79(72.5)$ \\
Diploma & $7(6.4)$ \\
Higher than diploma & \\
Marital status & $5(4.6)$ \\
Single & $102(93.6)$ \\
Married & $2(1.8)$ \\
Unknown &
\end{tabular}

${ }^{1}$ In the status of Unknown, workers have not specified their marital status in the questionnaire

occupational accidents among the workers of a foundry unit in Iran. The risk perception score of workers with an occupational accident record was higher than those without an occupational accident record. However, the observed difference was not statistically significant between both groups. One of the reasons for this nonsignificant difference may be the small sample size used in this study.

The results obtained by the present study are parallel to those obtained by Cezar-Vaz et al. who carried out a similar study among apprentice welders. Their results indicated that apprentice welders with an occupational accident record had higher risk perception than those without an occupational accident record [15]. In another study carried out by Cezar-Vaz et al., to identify risk perception and the types of occupational accidents among gas station workers, the perception of chemical risk was reported more among workers having records of chemical risk-related occupational accidents [16]. In a study done by Rundmo with the purpose of investigating the relationship between risk perception, job stress, and the frequency of accidents and near-accidents among petroleum personnel, it was observed

Table 3 Distribution of foundry workers by occupational accident occurrence $(N=109)$ in Tehran, Iran, 2016

\begin{tabular}{ll}
\hline Occupational accident occurrence & $N(\%)$ \\
\hline Yes & $51(46.8)$ \\
No & $58(53.2)$ \\
Total & $109(100.00)$ \\
\hline
\end{tabular}


Table 4 Distribution of the number of occupational accidents in the injured foundry workers ( $N=51)$ in Tehran, Iran, 2016

\begin{tabular}{ll}
\hline Occupational accident frequency & $N(\%)$ \\
\hline 1 & $34(66.67)$ \\
2 & $7(13.72)$ \\
3 & $8(15.69)$ \\
4 & $1(1.96)$ \\
5 & $0(0.00)$ \\
6 & $0(0.00)$ \\
7 & $1(1.96)$ \\
\hline
\end{tabular}

that job stress and risk perception have a significant contribution in the rate of human errors and injuries (25\% of the dependent variable variation was described by the independent variable $\left.\left(R^{2}=0.25\right)\right)$ [17].

It is expected that by increasing an individuals' risk perception, the occurrence of occupational accidents will be reduced [1]. Conversely, it should be taken into account that the occurrence of occupational accidents can also increase an individual's risk perception [18].

\subsection{Study limitations}

The relatively small sample size due to the screening of the workers in terms of mental health, the impossibility of evaluating the risk perception of workers before an occupational accident, and the inability to perform statistical tests to investigate the cause and time of accident occurrence due to the small sample size is considered as some limitations of the present study.

Risk perception is a human factor; hence, in order to investigate the relationship between risk perception and occupational accidents, it is proposed that only the accidents caused by human factors, i.e., unsafe acts, be considered. In addition, in order to obtain information about the effect of risk perception on occupational accident occurrence, it is suggested that the risk perception of individuals be assessed before the occurrence of occupational accidents.

\section{Conclusion and recommendation}

The present study found no significant relationship between the risk perception score with the occurrence and frequency of occupational accidents. The researchers

Table 5 Descriptive statistics for foundry workers' risk perception score by injury occurrence $(N=109)$ in Tehran, Iran, 2016

\begin{tabular}{lllll}
\hline Injury & Min & Mean \pm SD & Max & $p$ value \\
\hline Injured & 2.32 & $2.84 \pm 0.26$ & 3.42 & 0.699 \\
Not injured & 2.29 & $2.82 \pm 0.26$ & 3.27 & \\
Total & 2.29 & $2.83 \pm 0.26$ & 3.42 & \\
\hline
\end{tabular}

Table 6 Results of logistic regression analysis for assessing the relationship between risk perception score and occupational accident occurrence of foundry workers in Tehran, Iran, 2016

\begin{tabular}{llllll}
\hline $\begin{array}{l}\text { Independent } \\
\text { variable }\end{array}$ & $\begin{array}{l}\text { Coefficient } \\
\beta\end{array}$ & $\begin{array}{l}\text { Standard } \\
\text { error }\end{array}$ & $\begin{array}{l}p \\
\text { value }\end{array}$ & Odds ratio & $\begin{array}{l}95 \% \\
\text { confidence } \\
\text { interval }\end{array}$ \\
\hline $\begin{array}{l}\text { Risk perception } \\
\text { score }\end{array}$ & 0.29 & 0.742 & 0.695 & 1.337 & $0.312-5.724$ \\
\hline
\end{tabular}

recommend conducting studies with a larger sample size to assess the aforementioned relationship with more accuracy.

Investigating the relationship between risk perception and occupational accidents and paying attention to this relationship in preventive programs could play an important role in the control of occupational accidents in the future.

\section{Acknowledgements}

This manuscript has been adopted from Fahimeh Saghi's M.Sc. dissertation, under the supervision of Dr. Mohammad Javad Jafari and with the advice of Dr. Ebrahim Alizadeh and Dr. Farid Zayeri. The authors of this article sincerely appreciate the cooperation extended by the authorities and workers of the foundry unit and the authorities of Shahid Beheshti University of Medical Sciences.

\section{Authors' contributions}

All authors have made contributions to the conception and design of the study. FS collected the research data. FZ conducted the analysis and interpretation of data. FS wrote the manuscript and MJJ, FZ, and EA revised it. All authors read and approved the final manuscript.

\section{Funding}

This study has been funded by the corresponding author.

Availability of data and materials

Data can be made available from the corresponding author upon request and with the permission of foundry authorities.

\section{Ethics approval and consent to participate}

The study protocol was approved by the research ethics committee at Shahid Beheshti University of Medical Sciences, Tehran, Iran (IRB no. IR.SBMU.PHNS.REC.1395.31).

The study proposal was presented to the managerial body of the foundry and their approval was obtained prior to carrying out the study (such as informed written consent of participants to take part in the study, the anonymity of the applicants, and the confidentiality of information related to the participants) were considered during all stages of the study.

Consent for publication

Not applicable.

\section{Competing interests}

The authors declare that they have no competing interests.

\section{Author details}

${ }^{1}$ Department of Occupational Health Engineering, School of Public Health and Safety, Shahid Beheshti University of Medical Sciences, Tehran, Iran. ${ }^{2}$ Department of Applied Psychology, Faculty of Education and Psychology, Shahid Beheshti University, Tehran, Iran. ${ }^{3}$ Proteomics Research Center and Department of Biostatistics, Faculty of Paramedical Sciences, Shahid Beheshti University of Medical Sciences, Tehran, Iran. 
Received: 29 January 2019 Accepted: 5 September 2019

Published online: 28 November 2019

References

1. Ghahramani A, Abbasi A. Assessment of the relationship between occupational accident experience and personal and job factors in tar paper manufacturing companies. Iran Occup Health. 2016;12:48-57.

2. International Labor Organization (ILO). World Statistic: the enormous burden of poor working conditions; [cited 2018 Aug 18]. http://www.lo.org/ moscow/areas-of-work/occupational-safety-and health/WCMS_249278/ lang\%2D\%2Den/index.htm.

3. Jahangiri M, Sareban Zadeh K, Bashar O, Saleh Zade H. Investigation risk perception, safety attitude and safety performance in supervisors of construction sites Shiraz-Iran. Iran J Ergon. 2013;1:10-8.

4. Jafari M, Kouhi F, Movahedi M, Allah-Yari T. The effect of job safety analysis on risk perception of workers at high risk jobs in a refinery. Iran Occup Health. 2010;6:12-25.

5. Arezes PM, Miguel AS. Risk perception and safety behaviour: a study in an occupational environment. Safety Sci. 2008;46:900-7.

6. Xia N, Wang X, Griffin MA, Wu C, Liu B. Do we see how they perceive risk? An integrated analysis of risk perception and its effect on workplace safety behavior. Accid Anal Prev. 2017:106:234-42.

7. Neissi A, Hashemi Sheykhshaba E, Rahimi Pordanjani T, Arshadi N, Beshlideh K. Investigating personal, cognitive and organizational variables as predictors of unsafe behaviors among line workers in an industrial company. J Health Saf Work. 2013:3:13-26.

8. Jahangiri M, Sareban Zadeh K, Bashar O, Saleh Zade H. Investigating effective factors on risk perception, safety attitude and safety performance of construction workers of Shiraz city, 2012. J Health Field. 2017;1:30-6.

9. Zakaria AM, Noweir KH, El-Maghrabi G. Evaluation of occupational hazards in foundries. J Egypt Public Health Assoc. 2005;80:433-62.

10. Fathi Ashtiani A, Dastani M. Psychological tests: evaluation of personality and mental health. 3rd ed. Tehran: Besat; 2009. p. 321-325.

11. Yaghoobi H. Mental disorders screening: the situation of tests and determining their cut off score and validation. Q J Ment Health. 2008;1:39-51.

12. Nazifi M, Mokarami H, Akbaritabar A, Faraji Kujerdi M, Tabrizi R, Rahi A. Reliability, validity and factor structure of the Persian translation of General Health Questionnaire (GHQ-28) in hospitals of Kerman University of Medical Sciences. Journal of Fasa University of Medical Sciences/ Majallah-i Danishgah-i Ulum-i Pizishki-i Fasa. 2014;3:336-42.

13. Noorbala AA, Mohammad $K$. The validation of general health questionnaire28 as a psychiatric screening tool. Hakim Res J. 2009;11:47-53.

14. Soltani M. Determining the efficacy of safety educational intervention on the risk perception of an electronic industries employees [dissertation]. Tehran: Shahid Beheshti University of Medical Sciences; 2016. (Iranian)

15. Cezar-Vaz MR, Bonow CA, Rocha LP, de Almeida MCV, Severo LO, Borges AM et al. Risk communication as a tool for training apprentice welders: a study about risk perception and occupational accidents. Sci World J. 2012;2012:10.

16. Cezar-Vaz MR, Rocha LP, Bonow CA, da Silva MRS, Vaz JC, Cardoso LS. Risk perception and occupational accidents: a study of gas station workers in Southern Brazil. Int J Environ Res Public Health. 2012;9:2362-77.

17. Rundmo T. Risk perception and safety on offshore petroleum platforms _Part II: Perceived risk, job stress and accidents. Safety Sci. 1992;15:53-68.

18. Taylor WD, Snyder LA. The influence of risk perception on safety: a laboratory study. Safety Sci. 2017:95:116-24.

\section{Publisher's Note}

Springer Nature remains neutral with regard to jurisdictional claims in published maps and institutional affiliations.

\section{Submit your manuscript to a SpringerOpen ${ }^{\circ}$ journal and benefit from:}

- Convenient online submission

- Rigorous peer review

- Open access: articles freely available online

- High visibility within the field

- Retaining the copyright to your article

Submit your next manuscript at $\boldsymbol{\nabla}$ springeropen.com 